\title{
enjoy.et: UM ARTEFATO BASEADO EM TRANSMEDIA STORYTELLING PARA O ENSINO DE PROGRAMAÇÃO PARA CRIANÇAS
}

\author{
Tancicleide C. S. Gomes ${ }^{1}$, Patricia C. A. Restelli Tedesco ${ }^{1}$ \\ ${ }^{1}$ Centro de Informática - Universidade Federal de Pernambuco (UFPE) - \\ Recife - PE - Brasil \\ tancicleide.gomes@gmail.com. pcartecin.ufpe.br
}

\begin{abstract}
Computational thinking has been considered an important set of skills for the whole society. For this reason, Elementary Education and Early Childhood Education are potential candidates to ensure that everyone can not only learn basic language and mathematics, but also develop these skills. This work presents an educational artifact developed with the goal of supporting education for young children. The toolkit was developed based on the results of an action research conducted over the course of three years.
\end{abstract}

Resumo. O pensamento computacional tem sido considerado um conjunto de habilidades importantes para toda a sociedade. Por este motivo, o Ensino Fundamental e a Educação Infantil são potenciais candidatos para garantir que todos possam aprender não apenas linguagem e matemática básica, mas desenvolver também estas habilidades. Neste sentido, o presente trabalho apresenta um artefato educacional desenvolvido com o objetivo de dar suporte ao ensino de conceitos de programação para crianças pequenas. $O$ toolkit foi desenvolvido a partir dos resultados de uma pesquisa-ação realizada ao longo de três anos.

\section{Introdução}

O pensamento computacional tem sido popularizado a partir de iniciativas como o Hour of Code ${ }^{1}$, Computer Science for All ${ }^{2}$, Nerds da Fronteira ${ }^{3}$, entre outros. Os projetos pioneiros mais conhecidos envolvem manipulativos, robôs educacionais e linguagens de programação visual como a $\mathrm{LOGO}^{4}$ e mais recentemente o Scratch e o App Inventor ${ }^{6}$. Projetos como estes são relevantes por demonstrarem que a Ciência da Computação tem se tornado parte do cotidiano de uma parcela cada vez maior de pessoas ao redor do mundo - e tem se feito presente cada vez mais cedo para toda a sociedade.

Em todo o mundo, muitos países passaram a adotar a Ciência da Computação como componente curricular desde as séries iniciais da Educação Básica [Kafai e Burke 2013]. Sendo assim, o Ensino Fundamental e mesmo a Educação Infantil se revelam como potenciais candidatos para garantir que todos possam aprender desde cedo as habilidades relacionadas ao pensamento computacional [Guzdial 2015]. Neste sentido, existem diversos trabalhos que versam sobre as particularidades relacionadas ao ensino de programação para crianças [Falcão e Barbosa 2015;

\footnotetext{
${ }^{1}$ https://hourofcode.com/pt

${ }^{2}$ https://www.csforall.org/

${ }^{3}$ http://nerdsdafronteira.com/

${ }^{4}$ http://el.media.mit.edu/logo-foundation/

${ }^{5}$ https://scratch.mit.edu/

${ }^{6} \mathrm{http}$ ://appinventor.mit.edu/explore/
} 
VII Congresso Brasileiro de Informática na Educação (CBIE 2018)

Anais do XXIX Simpósio Brasileiro de Informática na Educação (SBIE 2018)

Gomes, Falcão e Tedesco 2018; Comes, Castro e Alencar 2017; Morgado 2005; Raabe et al. 2015].

Neste trabalho apresentamos um protótipo de baixa fidelidade resultante de uma pesquisa-ação desenvolvida ao longo de três anos (2015-2017). Em seu estágio atual, o protótipo contempla algumas das lacunas observadas na literatura [Gomes, Castro e Tedesco 2017] e incorpora alguns dos resultados observados na pesquisa-ação. Este trabalho pode ser relevante para educadores, pesquisadores e desenvolvedores interessados na concepção, desenvolvimento e avaliação de artefatos inovadores para o desenvolvimento do pensamento computacional, sobretudo por meios de conceitos de programação.

Organizamos este trabalho da seguinte maneira: na seção 2 apresentamos o conceito de transmedia storytelling, no qual baseamos o protótipo. Na seção 3 apresentamos e discutimos o protótipo desenvolvido, e na seção 4 discutimos, respectivamente, sobre as limitações, os trabalhos futuros, e as considerações finais.

\section{Transmedia Storytelling}

O termo, cunhado por Jenkins (2007) compreende diversas histórias contadas por meios distintos de maneira autônoma, complementando-se para formar uma narrativa mais ampla: "Transmedia storytelling represents a process where integral elements of a fiction get dispersed systematically across multiple delivery channels for the purpose of creating a unified and coordinated entertainment experience. Ideally, each medium makes it own unique contribution to the unfolding of the story." $\mathrm{O}$ transmedia storytelling oferece uma experiência diferente em cada um dos elementos estruturantes, de modo que "o todo não seja apenas a soma de suas partes". A narrativa mais ampla se desdobra em cada um dos elementos presentes e promove uma experiência única em cada um deles, de modo que embora não sejam interdependentes são complementares. Isto permite que possamos nos apropriar das especificidades de cada elemento estruturante para oferecer uma experiência mais rica e engajadora.

\section{Toolkit Educacional para Ensino de Conceitos de Programação para Crianças}

Os docentes da Educação Infantil tendem a usar menos as tecnologias digitais, porque muitas proporcionam o oposto do que as crianças precisam nesta fase. Neste sentido, o toolkit visa abordar as principais necessidades educacionais de crianças pequenas (ex. atividades em pares, interações sociais adulto-criança, aprendizagem prática e outras), em detrimento da simples incorporação de materiais educacionais baseados em tecnologias digitais que tendem a privilegiar os conteúdos curriculares, em vez da diversão, inventividade e imaginação.

Mediante este cenário, elaboramos um toolkit educacional para promover o pensamento computacional por meio de práticas de programação na Educação Infantil. Este artefato resultou de uma pesquisa-ação educacional realizada ao longo de três anos (2015-2017) em uma escola da rede particular de ensino em Recife, Pernambuco com aproximadamente 200 crianças com idades entre quatro e sete anos [Comes, Castro e Tedesco 2017; Comes, Pontual Falcão e Tedesco 2018]. O protótipo do toolkit apresentado neste trabalho baseia-se nos elementos estruturantes de transmedia storytelling e incorpora em um mesmo artefato: jogo digital, livro e brincadeira no intuito de apresentar o pensamento computacional.

O toolkit fundamenta-se nos princípios de transmedia storytelling e tem como cerne uma narrativa principal que se desdobra em seus três elementos: livro, jogo digital e brincadeira. $\mathrm{E}$ assim, o toolkit permite que: (a) os educadores possam escolher quais elementos serão adotados, em que ordem e e como serão apresentados, considerando uma determinada situação de aprendizagem; (b) os diversos estilos de aprendizagem sejam contemplados, permitindo aos alunos explorarem os conceitos apresentados a partir de diferentes possibilidades, perspectivas e experimentações. Os principais diferenciais do toolkit são: (1) apresentar os conceitos de programação de maneira situada, significativa e tangencial; (2) incorporar as vozes e ações dos 
VII Congresso Brasileiro de Informática na Educação (CBIE 2018)

Anais do XXIX Simpósio Brasileiro de Informática na Educação (SBIE 2018)

atores envolvidos no processo educacional (alunos e professores) por meio da pesquisa-ação; (3) permitir a experimentação e o uso do pensamento computacional sob diferentes perspectivas e modalidades, devido aos seus distintos componentes.

O projeto, ainda em 2017, recebeu a chancela $\mathrm{a}^{7}$ da $\mathrm{SBC}$ em reconhecimento à sua proposta inovadora para a disseminação da Ciência da Computação na Educação Básica.

\subsection{Aspectos Instrucionais}

O toolkit se ancora no conceito de Zona de Desenvolvimento Proximal (ZDP) de Vygotsky, compreendendo a ludicidade como elemento crucial para as crianças aprenderem com adultos oferecendo suporte, compartilhando ideias e estratégias [Kishimoto 2016]. Este suporte permite que a criança se desenvolva a partir de habilidades ou conhecimentos existentes, mais do que apenas tentar apresentar ideias completamente novas.

Assim, as situações-problemas propostas abordam conceitos de programação de maneira lúdica e tangencial envolvendo elementos conhecidos pelas crianças, com o suporte dos adultos para aprender. Utilizamos como referência as habilidades e competências relacionadas aos conceitos de Algoritmos e Programação relatadas no currículo CSTA K-12 Computer Science Standards (2017) para a Educação Infantil. ${ }^{8}$

\subsection{Pensamento Computacional para ser Lido: O eixo livro}

Os livros necessitam de uma audiência que preencha as lacunas sensoriais encontradas no texto, como fisionomias, vozes e cenários, um dos motivos pelo qual o escolhemos como componentes do toolkit. Assim, as crianças podem se apoderar da história, aplicando seus próprios arquétipos e tornando-a sua, e assim, a narrativa pode facilmente ser extrapolada e ampliada em sala de aula sob mediação do professor. O enredo proposto no livro tem como principais objetivos: (O1) colocar a criança como protagonista, líder, idealizadora e tomadora de decisões; (O2) inserir crianças, homens e mulheres, com ou sem deficiências intelectuais, físicas e motoras; (O3) promover valores essenciais à vivência em sociedade, como: amizade, amor, paciência, companheirismo.

Para escolher a temática, convidamos professoras da Educação Infantil a avaliar temas que tivessem apelo para ambos os gêneros. Selecionamos a temática pirata devido ao seu potencial para a criação de situações-problema, para estimular a criatividade e a imersão. Mesmo porque piratas agem em coletivo e possuem um sentimento de companheirismo: formam uma tripulação que deve trabalhar colaborativamente em prol de objetivos compartilhados.

A decisão pela inserção do componente fantástico deu-se porque estudos apontam maior eficácia no aprendizado de crianças submetidas à obras de fantasia ${ }^{9}$, permitindo a criação de paralelos e comparações com a realidade, levando à abstração dos conceitos, algo importante no ensino do pensamento computacional.

\subsection{Pensamento Computacional para ser Jogado: $O$ eixo jogo}

Os jogos digitais podem oferecer experiências interativas que promovem o desenvolvimento de habilidades e competências, a aprendizagem de conceitos e um desenvolvimento saudável [Lieberman, Fisk e Biely 2009]. Segundo estes autores, os jogos projetados para crianças pequenas não reconhecem as maneiras pelas quais elas aprendem e brincam, assim como poucos são testados para garantir que sejam divertidos e educacionalmente efetivos.

\footnotetext{
${ }^{7}$ http://www.sbc.org.br/institucional-3/chancela-sbc/enjoy-et-computacao-para-ler-brincar-e-jogar

8 http://bit.ly/2MFIfCB

${ }^{9}$ http://bit.ly/2ORHF6b
} 
VII Congresso Brasileiro de Informática na Educação (CBIE 2018)

Anais do XXIX Simpósio Brasileiro de Informática na Educação (SBIE 2018)

No toolkit, o jogo digital oferece situações-problema traçadas no cotidiano envolvendo sequências de instruções, condicionais, laços de repetição e depuração, usados para interagir com os personagens da narrativa. A versão atual explora a continuidade, ao abordar a narrativa a partir da perspectiva da personagem principal do livro.

\subsection{Pensamento Computacional para ser Experimentado: $\mathrm{O}$ eixo brincadeiras}

As crianças mais novas são intrinsecamente motivadas a brincar e explorar. $\mathrm{O}$ ato de brincar consiste em uma das principais maneiras pelas quais elas aprendem, desenvolvendo a iniciativa, expressando seus desejos e internalizando regras sociais, ao assumir o papel de outra pessoa, realizando as suas ações e estabelecendo suas relações típicas, incorporando elementos adquiridos do contexto cultural.

Utilizamos as brincadeiras para desenvolver habilidades do pensamento computacional, tornando a coexistência entre o lúdico e o educacional não conflitante. Criamos oportunidades das crianças explorarem as situações trazidas pela narrativa, recriando a realidade por meio de sistemas simbólicos próprios. As brincadeiras basearam-se em dinâmicas de brincadeiras tradicionais, combinando mecânicas e elementos comuns aos elementos e personagens da narrativa.

\section{Considerações Finais}

O desenvolvimento do pensamento computacional na educação infantil tem alcançado uma ampla notoriedade nos últimos anos e existe uma vasta gama de materiais educacionais relacionados. No entanto, muitos dos artefatos existentes não permitem contemplar importantes elementos que contribuem para o desenvolvimento cognitivo, social e emocional das crianças.

Mediante o exposto, este trabalho apresentou um protótipo de um toolkit educacional que visa apoiar a disseminação do pensamento computacional para crianças na educação infantil por meio de práticas de programação. Um dos principais diferenciais deste trabalho consiste em apresentar os conceitos de programação a partir de uma abordagem tangencial em uma perspectiva multimidiática, apresentando-se como uma proposta inovadora para proporcionar o desenvolvimento de habilidades e competências do pensamento computacional associadas à promoção do desenvolvimento cognitivo, social e emocional das crianças. ]

O protótipo foi desenvolvido a partir dos resultados obtidos ao longo da pesquisa-ação e considerando referenciais teóricos sobre o desenvolvimento infantil [Kishimoto 2016]. No entanto, alguns de seus componentes não foram avaliados em sala de aula: (a) o jogo digital considera as diretrizes propostas por Comes, Castro e Tedesco (2017) mas ainda consiste em um protótipo de baixa fidelidade e portanto não foi avaliado com os alunos - por este motivo, aspectos como jogabilidade e usabilidade foram contemplados apenas a partir da perspectiva de especialistas; (b) o livro foi elaborado com e avaliado por professoras de Educação Infantil, mas não foi utilizado em sala de aula; (c)outro aspecto refere-se ao restrito leque de artefatos incorporados no protótipo, podendo limitar o uso.

Os próximos passos consistem em concluir o protótipo apresentado: aprimorar as ilustrações e produzir o livro impresso; concluir o desenvolvimento do jogo digital, entre outros. Serão realizadas avaliações de usabilidade e jogabilidade, a partir dos modelos propostos por Lieberman, Fisk e Biely (2009) por meio de parcerias com professores de escolas particulares e públicas em Recife e região metropolitana.

\section{Agradecimentos}

O presente estudo foi desenvolvido durante o mestrado, parcialmente financiado pelo CNPq. As autoras agradecem à Fernanda Castro pela elaboração das narrativas; à Jéssica Porfírio pelas ilustrações e à Mychelline Cunha, pela prototipação do jogo digital. 
VII Congresso Brasileiro de Informática na Educação (CBIE 2018)

Anais do XXIX Simpósio Brasileiro de Informática na Educação (SBIE 2018)

\section{Referências}

Falcão, T.P., e Barbosa, R. "Aperta o Play!" Análise da Interação Exploratória em um Jogo Baseado em Pensamento Computacional. In: Anais do Simpósio Brasileiro de Informática na Educação.2015. p. 419.

Gomes, T. C. S., Falcão, T. P., e Tedesco, P. C. A. R. (2018). Exploring an approach based on digital games for teaching programming concepts to young children. International Journal of ChildComputer Interaction.

Comes, T., Castro, F. e Tedesco, P. C. A. R. Desenvolvendo o Pensamento Computacional na Educação Infantil: Um toolkit educacional sobre conceitos de programação baseado em storytelling transmedia. In: Sánchez, J. (2017) Editor. Nuevas Ideas en Informática Educativa, Volumen 13, p. 31 - 40. Santiago de Chile.

Comes, T., Castro, M.F., e Alencar, A. Evaluating the effectiveness of educational games: a digital game-based approach to teach programming concepts for kindergarteners. In: Simpósio Brasileiro de Informática na Educação. 2017. p. 574.

Gomes, T., Melo, J., e Tedesco, P. (2016) Jogos Digitais no Ensino de Conceitos de Programação para Crianças. In: Simpósio Brasileiro de Informática na Educação. p.420.

Guzdial, M (2015). Learner-centered design of computing education: Research on computing for everyone. Synthesis Lectures on Human-Centered Informatics, 1-165.

Jenkins, H. (2007) Transmedia Storytelling 101. Disponível em: http://henryjenkins.org/blog/2007/03/transmedia_storytelling_101.html. Acessado em 20/08/2018.

Kafai, Y.B., e Burke, Q. (2013).Computer programming goes back to school. Phi Delta Kappan, 95(1), 61-65.

Lieberman, D. A., Fisk, M. C., e Biely, E. (2009). Digital games for young children ages three to six: From research to design. Computers in the Schools, 26(4), 299-313.

Morgado, L. C. (2005) Framework for computer programming in preschool and kindergarten. Dissertação de Mestrado. Universidade de Trás-os-Montes e Alto Douro (Portugal).

Raabe, A., Rodrigues, A.J., Santana, A.M., Vieira, M.V., Rosário,T. e Carneiro, A.C.R.(2015)Brinquedos de Programar na Educação Infantil: Um Estudo de Caso. In: Anais do Workshop de Informática na Escola. p. 42. 